\title{
Editorial
}

\section{Sin sucesión no hay continuidad}

\section{GIUSEPPE VANONI-MARTÍNEZ*}

En el mundo de las empresas familiares ninguna es igual a otra, cada una tiene sus particularidades y características que las hace únicas. Son las diferencias en la cultura, las distintas legislaciones gubernamentales y la diversidad de problemas de índole familiar y organizacional, lo que hace que se comporten de diferente manera. De forma paralela a lo mencionado, este tipo de empresas coinciden con una creciente importancia económica social e institucional en Colombia.

En los últimos treinta años se ha valorado la necesidad de que los aspectos familiares sean adecuadamente gestionados; y entre ellos, posiblemente, uno de los más sensibles para la perdurabilidad de las organizaciones familiares es el proceso de sucesión debido a las implicaciones de incertidumbre tanto internas como externas que se presentan en esta tipología empresarial al momento de querer realizar el cambio de mando.

Por esta razón, un mal proceso de sucesión es considerado como una de las principales causas de fracaso en el crecimiento y longevidad de las empresas familiares. Siendo la falta de planificación, el motivo por el cual solo un 30 $\%$ de ellas sobreviven a la segunda generación; incluso cuando planificar el cambio en la dirección lleva implícito decisiones que afectan al gobierno, a la gestión y a la propiedad familiar.

Así pues, una sucesión bien ordenada estará relacionada tanto con la preparación de quienes tomaran el liderazgo como con la evolución de la organización de la empresa. Bajo estas circunstancias, los riesgos y las oportunidades presentes en el contexto exigen un enfoque en su accionar por parte del director de la organización; de no ser así podría poner en dificultades su permanencia en el sector, la industria o el propio mercado.
COMO CITAR ESTE ARTÍCULO

How to cite this article:

Vanoni-Martínez, G. (2019). Editorial. Sin sucesión no hay continuidad. Revista Perspectiva Empresarial, 6(1), 3-5.

* Doctor en Ciencias de la Dirección. Profesor-investigador. CEIPA, Business School, Sabaneta, Colombia. E-mail: giuseppe.vanoni@ceipa.edu.co. ORCID: 0000-0002-9884-066X. Google Scholar: https://scholar.google.com/ citations?hl=en\&user=Jsi28EwAAAAJ. 
Pero ¿por qué la sucesión del mando genera tanta controversia? ¿Acaso es por la resistencia natural al cambio generacional o por miedo de parte del fundador a perder el control? Con el objetivo de minimizar esas inquietudes, entre las distintas aproximaciones que se pueda tener al respecto, hay que resaltar que una correcta gestión de incorporación estará ligada a la presencia de tres protagonistas clave que deben de considerarse en dicho proceso y sobre los cuales se debe crear una ruta adecuada para minimizar este efecto.

El sucesor: escogerlo comienza desde muy temprana edad. Desde casa se le debe enseñar a amar a la empresa familiar, despertando una vocación; una buena manera de hacerlo es generando programas de rotación empresarial en los períodos de descanso de las actividades académicas, con ello pueden conocer lo que sucede en la organización en profundidad. Posteriormente a la culminación de su carrera universitaria se debe tomar la decisión de sugerirles a los hijos que trabajen en otras empresas, sean estas familiares o no, distintas a la propia. Si bien esto puede ser una recomendación difícil para los padres empresarios, es muy importante para que adquieran experiencias previas y para generar confianza en los empleados de la empresa familiar que ven a un sucesor con las competencias y habilidades necesarias para la toma de decisiones.

La empresa: la llegada de un sucesor a la empresa familiar genera menos impactos y crisis cuando esta previamente ha estado organizada con una junta general de accionistas, un consejo de administración y un consejo de dirección que se reúnen y funcionan de manera adecuada. Cosa distinta sucede cuando el sucesor llega a una empresa en la que el fundador ha construido una organización a su imagen y semejanza; con colaboradores que solo ellos entienden la forma de ver los negocios, que comparten su estilo de dirección y liderazgo junto con una estructura que bien o mal responde al sector en que se desenvuelven. En una empresa conformada así, un sucesor con experiencia y formación técnica de alta dirección difícilmente podrá dirigirla con eficiencia; por ello hay que preparar a la empresa comenzando con la descentralización de la toma de decisiones, creando mecanismos de coordinación que unan esfuerzos entre los especialistas de cada área y definiendo distintas funciones de dirección con sus respectivos responsables. Esto lleva a la conformación de un organigrama formal que muy posiblemente antes no hacía falta con el estilo de organización informal del fundador y que hoy exige la conformación de modernos sistemas de control de gestión, de información, de comunicación, de evaluación del desempeño con sistemas de compensación y promoción; basados en objetividad y racionalidad y no en emociones, algo que en una empresa familiar es muy complicado. Finalmente pensar en un sistema de retención del talento humano, hay que conseguir que el personal se sienta vinculado a la empresa familiar. La arquitectura de esta nueva organización debe ser gobernada mediante la construcción de órganos de gobierno, dos principales, y dependiendo del tamaño de la empresa serán: el comité de dirección para coordinar actividades funcionales y un consejo de administración que regule la acción directiva.

La familia: de manera inevitable la sucesión del fundador afecta también a la familia, incidiendo sobre el tipo de relaciones familiares que existían antes de iniciar dicho proceso. Hay que preparar a la familia para ese cambio de relaciones, con las nuevas que es la del equipo de hermanos, que serán muy distintas y complejas a las que se presentaban en la etapa del propietario controlador. Los temas que de manera recurrente aflorarán en este momento de sucesión son: (i) poder, ¿quién lo tendrá y cómo lo ejercerán?; (ii) en lo referente al trabajo, ¿quién trabajará y en qué posiciones?; (iii) el reparto de los recursos generados, principalmente por la presencia de accionistas activos y aquellos que no están en el día a día de la gestión y (iv) ¿qué mecanismos se emplearán para la trasferencia de la propiedad? La mejor manera de tener alguna probabilidad de éxito para todo lo anterior es dotarse de estructuras (tales como el consejo de familia y el family office) que cuiden el capital no sujeto al riesgo del negocio principal -o si la familia tendrá acciones de filantropía-.

Estos tres protagonistas clave nos llevan a pensar en cinco factores que inciden directamente sobre las inquietudes mencionadas y presentes en la sucesión del mando:

1. La falta de información: para la correcta implementación de un plan de sucesión la información es uno de los principales factores que 
provocan resistencia al cambio. Por ello contar con información es imprescindible para el adecuado manejo de ciertas situaciones familiares y porque elimina las ambigüedades típicas de todo proceso de cambio.

2. La cultura empresarial: el rechazo al sucesor se puede dar por la propia idiosincrasia y por la forma de ver las cosas de las generaciones previas, principalmente si el sucesor es externo.

3. Amenaza al statu quo: en muchas empresas el cambio estructural es visto como una amenaza a la zona de confort en las que muchos familiares y colaboradores están. Incluso confort que seguramente también alcanzó el propio fundador de la empresa, que ve como una gran amenaza cualquier intento de modificar lo que históricamente se ha hecho.
4. Retención del poder: principalmente por los grupos (familiares o no) que se han formado durante la trayectoria de la empresa. Ellos pueden ser los principales saboteadores de la sucesión.

5. Miedo al fracaso: puede generarse en el hecho respecto a que tan viable puede resultar la sucesión y si es el momento idóneo para llevar a cabo el proceso.

La sucesión como hemos podido observar debe ser vista como un proceso, más no como un suceso, por lo que su preparación debe de ser realizada con el suficiente tiempo para observar los mejores candidatos e involucrarlos así en la organización y realizar una etapa de trabajo conjunto - fundador-sucesor- que minimice el impacto y las crisis que son propias de la transferencia del mando en cualquier empresa. 